\title{
EDUCAR ADULTOS MAIORES NA ÁREA DA EDUCAÇÃO SOCIAL: A INTERGERACIONALIDADE NUMA SOCIEDADE PARA TODAS AS IDADES
}

\author{
ERnesto CandeIAs Martins \\ Instituto Politécnico de Castelo Branco, Castelo Branco, Portugal
}

\begin{abstract}
Resumo: O tema da educação dos adultos e/ou adultos maiores merece uma reflexão epistemológica, em relação à ação dos profissionais, nas diversas valências na rede social e comunitária, como nas instituições educativas. Utilizando uma argumentação hermenêutica, o autor aborda a necessidade de implementar propostas socioeducativas para os adultos maiores, por meio de programas intergeracionais, destacando o papel da gerontologia educacional ou gerontagogia, a qual se integra no campo da educação social. Os objetivos que nortearam esta análise fenomenológica são: repensar a educação de adultos maiores, na área da gerontagogia; analisar os aspetos socioeducativos, psicopedagógicos e metodológicos nas ações e nos programas gerontológicos, com a finalidade de promover uma cidadania ativa. Refletiremos epistemologicamente as possibilidades educativas, provenientes da pedagogia social/ educação social e a gerontagogia, de modo a dar uma qualidade de vida aos adultos maiores, numa sociedade para todas as gerações. Palavras-Chave: Adulto maior. Gerontologia educacional. Educação social. Intergeracionalidade.
\end{abstract}

INTRODUÇÃO

No novo cenário demográfico há uma preocupação por parte das instituições de ensino, relacionadas com os 'adultos maiores', terminologia 
que adoptaremos em substituição de idoso, adultos tardios, terceira/quarta idade ou aposentados em proporcionar-lhes uma educação (gerontológica) nesse período de vida, no contexto do 'aprender a aprender ao longo da vida', constituindo-se no ideal das sociedades para todas as idades e, ainda numa necessidade de reconsideração do processo de envelhecer (ARNAY; MARRERO; FERNÁNDEZ, 2011, p. 91-98). Esta preocupação sobre a educação dos adultos maiores estende-se à área da intervenção da pedagogia social (a partir de agora PS) e/ou educação social (dimensão prática da PS), como uma temática de diagnóstico e materialização de projetos de intervenção socioeducativa, orientados a satisfazer a necessidades, no sentido do 'quê', 'como', 'quando', 'onde,',para quê' da educação nesses adultos maiores (BERMEJO, 2005). Fruto desse campo de ação emerge, por um lado certos profissionais para intervir no âmbito educativo e sociocultural com essas pessoas (gerontólogos sociais, gerontagogos, educador social, animador gerontólogo, psicogerontólogos, etc.) e, por outro lado, a criação de um espírito intergeracional (programas, projetos), com o intuito de materializar uma sociedade para todas as idades e gerações (MORENO; GARCÍA, 2003).

Esta diáspora exige uma articulação da 'educação' e da 'aprendizagem' nessas pessoas maiores e a convergência do desenvolvimento de políticas (educativas, sociais, assistenciais e culturais) adequadas aos problemas e necessidades desses coletivos (GARCÍA ;SANCHÉZ, 1998, p. 67-82). A participação destas pessoas em atividades ou tarefas diversas (educativas/ formativas, socioeducativas e socioculturais) constitui um meio gerador para a sua qualidade de vida e promotoras de um envelhecimento ativo. Ou seja, a participação, que se quer ativa, desenvolve novas capacidades e competências naquelas pessoas que envelhecem, previne os efeitos do deterioro físico-mental, o declive progressivo das 'perdas' e limitações nesse ciclo do percurso de vida (JARVIS, 1993). Essas finalidades devem ser de teor educativo e sociocultural, já que se pode aprender ao longo da vida. Neste novo cenário as pessoas que se aposentam e envelhecem são protagonistas e atores de uma nova 'cultura da velhice' (GIL CALVO, 2003, p. 78-93) ou melhor dito, de uma 'nova leitura e cultura de aprender'. 
O cerne da nossa argumentação reflexiva (epistemológica) é o de abordar a necessidade de implementar propostas socioculturais/socioeducativas para os adultos maiores, no campo da gerontologia educacional ou gerontagogia, considerando esta última uma alternativa àquela (e à andragogia), mas entrelaçadas no domínio da pedagogia/educação social, ao intentar responder às novas problemáticas e dificuldades sociais daqueles colectivos, com a finalidade de proporcionar uma nova forma de viver o envelhecimento e a velhice. Ou seja, a educação e o envelhecimento articulam-se na necessidade de promover uma aprendizagem ativa nas pessoas adultas maiores, com um tipo de educação/formação diferente da tradicional educação de adultos e/ ou andragogia (MARTINS, 2013). Situamos o nosso discurso na hermenêutica (pressupostos de compreensão da educação de adultos maiores), edificada na fenomenologia do envelhecimento, mas deslocando o eixo da interpretação para o problema social e educativo dos adultos maiores, em que o continuar a aprender é fundamental, para além de controversas (gerontologia educativa e gerontagogia) e pressupostos das teorias e práticas de aprendizagem nessas pessoas, o que exige alterações nos princípios da educação de adultos tradicional (AMORÓS et al., 2006, p. 16-24). A nossa abordagem centra-se na educação do 'adulto maior' com os seguintes objetivos:

-Repensar/redefinir a educação dos adultos maiores, dos seus processos de aprendizagem e partilha de experiências, na área da gerontagogia como alternativa à gerontologia educativa/educacional.

-Analisar a inclusão dos aspetos socioeducativos, psicopedagógicos e metodológicos nas ações e programas educativos/formativos, com a finalidade de promover um 'aprendiz adulto ativo', estratégico e autónomo (cidadania ativa) (DOWD, 1994, p. 25).

Uma das questões que devemos argumentar é o da contextualização e objetivos do significado duma educação 'nas' ou 'para' as pessoas adultas maiores na atualidade. Poucos estudiosos questionam essa possibilidade educativa, pois a materialização do princípio da educação permanente e/ou do aprender a aprender ao longo da vida é hoje uma realidade, apesar de haver pontos de vista distintos na base de teorias e conceitos, estratégias e metodologias na realização de programas edu- 
cativos orientados àquelas pessoas adultas maiores (ARNAY; MARRERO; FERNÁNDEZ, 2011, p. 90-95). O tema da educação dos adultos/adultos maiores merece uma reflexão epistemológica, em relação ao perfil e acção dos profissionais e/ou técnicos gerontológicos e educadores sociais, nas diversas valências na rede social vigente, como também das instituições educativas, na perspetiva de se criar programas para gerar comunidades de aprendizagem intergeracionais. No contexto desses paradigmas educativos, pretendemos reforçar o estatuto da pedagogia social (PS), realizando renovações e inovações educativas (programas educação intergeracional), provocando ruturas com as psicologias construtivistas e cognitivistas no conhecimento pedagógico dessas pessoas em situação de envelhecimento. Esse vaivém da educação - envelhecimento requer uma análise aos discursos da investigação gerontológica e da intervenção socioeducativa (universidades seniores, da $3^{\mathrm{a}}$ idade ou da experiência, aulas para adultos de idade avançada ou aposentados, etc.), à semântica e à preocupação da aprendizagem dessas pessoas (WITHNALL, 1992, p. 17-19). Tudo isto implica uma posição da PS, no campo do conhecimento teórico-prático e na genealogia do envelhecer ou da velhice 'sobre', 'de' e 'com' os adultos maiores. Haverá que extrair possibilidades educativas oriundas da análise relacional entre PS e gerontagogia.

\section{A EDUCAÇÃO DOS ADULTOS MAIORES NA PERSPETIVA DA PEDAGOGIA SOCIAL}

Baseamos o nosso discurso, neste ponto, num triplico de pontos: a relação entre PS e a gerontagogia; a polinização dos dois tipos de territórios/ discursos fundados na transversalidade da PS e da educação intergeracional; a intervenção educativa com as pessoas adultas maiores na área da gerontagogia na base das necessidades educativas desses sujeitos. Apostamos na PS, como campo de conhecimento teórico, que integra esses coletivos de cidadãos nas redes sociais do seu ambiente envolvente e itinerários culturais, promovendo através da educação social (prática da PS) a sua participação ativa, manutenção da autonomia e bem-estar (SÁEZ CARRERAS; ESCARBAJAL, 1998). Aquela pedagogia constitui uma matriz de áreas inerentes à educa- 
ção dos adultos maiores (gerontagogia) ou uma área significativa dentro das ciências da velhice, fundamentada na polinização das relações entre educação-aprendizagem. Há, pois, necessidade de investigações na educação dos adultos maiores para compreendermos os processos de aprendizagem associadas à essa idade, as teorias que pré-determinam as conceções e imagens sobre eles e a proposta de projetos educativos gratificantes.

Sabemos que muitas pessoas maiores têm razões e motivações para continuar a aprender; conhecer outras pessoas (relacionar-se); implicação em tarefas criativas e atividades estimulantes; necessidade de aprofundar saberes ou temáticas que Ihes interessa (ampliar horizontes); preencher algumas deficiências formativas anteriores; ocupação do tempo de modo produtivo (participação comunitária); desempenhar com mais competência certas ocupações (com ou sem remuneração); treinar a parte físico-cognitiva e emocional para se manter bem na sua idade (sonha da sua existência); readaptar-se às novas situações da aposentação ou jubilação; dar sentido e significado a este ciclo de vida (velhice); construir processos que lhe permita ir da dependência à independência; etc. (BLÁZQUEZ; HOLGADO, 2011, p. 132-139). Esses objetivos referidos justificam 'per si' a tarefa das instituições, dos grupos e associações, profissionais e voluntários para educar e facilitar os processos de (auto) aprender dessas pessoas no processo de envelhecimento que se quer ativo e satisfatório. As próprias investigações corroboram estas intenções, legitimando esta educação.

Pensamos que a educação para a terceira idade ou adultos maiores se está desenvolvendo cada vez mais, com um certo paralelismo com a educação de adultos não-profissional, redescobrindo outras formas de aprendizagem (permanente) para estes coletivos (CUENCA et al., 2011, p. 256-259). A partir da Assembleia Mundial do Envelhecimento, celebrado em Viena (1982), tem havido muitos progressos na promoção de processos de aprendizagem adequados para satisfazer as necessidades manifestadas ou latentes, implícitas ou explícitas dessas pessoas adultas tardias ou idade avançada. Assim, a educação dos adultos maiores, distinguindo-se da tradicional educação de adultos, aferrada a princípios curriculares de formação ou especialização laboral, surge em força com programas e projetos educativos em instituições 
públicas e particulares e na comunidade em geral, como um direito democrático e, principalmente como uma expressão da área da pedagogia social, considerada no âmbito da intervenção socioeducativa (MOSKOW-McKENZIE, 1995, p. 47-62; SORIA, 2012, p. 44-48).

Consideramos as possibilidades educativas, em diversas realidades sociais e culturais, num universo humano que pretende no encontro com as 'outras pessoas', com os saberes, as tradições, as práticas e experiências e vivências satisfazer o seu processo de envelhecimento (LÓPIS, 2002). Nesse cenário, os objetivos duma educação de adultos maiores integram-se na área do conhecimento da pedagogia social e/ou educação social (prática socioeducativa da pedagogia social), numa necessidade de investigar e intervir nos idosos, adultos maiores, pós-aposentados/jubilados e, principalmente no desvelar os processos de aprendizagem associados à idade ou percurso de vida, aos enfoques que predeterminam novas conceções e imagens da educação dos adultos maiores, no seu 'aprender a aprender', não só como direito adquirido, mas como necessidade nos novos contextos da sociedade do conhecimento e sociedade de aprendizagens (MORENO; GARCÍA, 2003, p. 99-103). As pessoas adultas maiores se gratificam e nos gratificam nos seus resultados e esforços de aprendizagem (não formal), nas diversas instituições que realizam intervenções socioeducativas.

Essa educação, designada em vários contextos por gerontagogia, dentro do chapéu da PS, constitui um contributo à participação dessas pessoas e na promoção da educação intergeracional. Há uma relação entre a pedagogia social com a educação de adultos e adultos maiores, que permite: aprofundar este tipo de educação, dentro das ciências da educação; analisar a socialização terciária e o fenómeno sociológico da explosão demográfica da 'maré cinzenta'; as políticas educativas orientadas a esse coletivo desde as instituições educativas, incluindo as de ensino superior na oferta formativa; o contributo do marco teórico da educação de adultos a esse tipo de educação aos adultos maiores; promoção da educação intergeracional e de programas comunitários intergeracionais, o que requer profissionais com uma profissionalização mais ampla (SÁEZ CARRERAS, 1996, p. 7). 
Intervenção gerontológica educativa: Do envelhecimento à educação

Começamos por explicar o termo de 'gerontologia educativa', que foi definida por D. Peterson (1976, p. 62), como sendo o estudo e a prática do ensino orientado às pessoas envelhecidas ou que já envelheceram, destacando três aspetos: intervenções educativas para adultos e adultos maiores; educação para todos ou específica para o envelhecimento e adultos maiores; preparação educativa das pessoas que desenvolvem atividades profissionais de atenção e apoio aos idosos ou adultos maiores (BERMEJO, 2005). A gerontologia educativa é um intento de incrementar e aplicar os saberes que se conhecem sobre a educação e o envelhecimento com a finalidade ampliar e melhorar a vida das pessoas maiores, ou seja, trata-se de: ensino dos adultos maiores que inclui a gerontologia instrutiva (teórica) e a educação dos adultos maiores (prática); ensino sobre a educação dos adultos maiores, sustentada teoricamente pela gerontologia social e pela prática gerontológica; formação dos profissionais e cuidadores, no âmbito teórico-prático da educação gerontológica (GLENDENNING, 1990). Esta clarificação semântica do termo permite-nos distinguir a parte teórica (investigação, enfoques teórico-concetuais, filosofia da velhice, conhecimentos, necessidades, implicações educativas, etc.) e a prática (design, planos, implementação, gestão e avaliação).

Mais tarde surgiu, a partir deste modelo de Peterson (1976), a posição de Radcliffe com a distinção entre a gerontologia educativa (aprendizagem nas pessoas adultas maiores - o que se educa a essas pessoas?) e educação gerontológica (ensino da gerontologia relacionado com o envelhecimento humano). Com essas propostas, F. Glendenning (1985, p. 35-41) clarificou os esforços e tarefas educativas (teórico-práticas) sobre estes coletivos, de modo que a gerontologia educativa compreendia a instrução (parte teórica - Como podem os adultos maiores aprenderem?'; parte prática -'A eficiência e eficácia da intervenção de modo a promover uma experiencia continua nesses adultos maiores'). Ora, essas propostas estão debilitadas pelo facto de que fala da gerontologia educativa na vertente de educação de adultos maiores e educação gerontológica ou como uma especialidade da gerontologia inserida no processo de envelhecimento (1990). Essa decisão epistemológica 
implica que a educação seja um processo dependente dos idosos e do seu envelhecimento, limitando a ideia de educação como processo (SÁEZ CARRERAS, 1996, p. 9-12). De facto, Glendenning (1990, p. 211-214) com Battersby intentou denominar a gerontologia educativa como gerogogia crítica, como forma dos idosos tomarem consciência dos seus direitos e qualidade de vida. Esta revolução alterou na prática os paradigmas tradicionais da gerontologia educativa para a emancipação e 'empowerment' dos adultos maiores.

Esta confusão terminológica parece procurar um marco teórico e prático, que mistura a educação de adultos, educação para os adultos maiores, andragogia, gerogogia, etc. É certo que a gerontologia educativa aspira como área de'gerontologia' a um novo paradigma de investigação sobre os adultos maiores, colocando o processo de envelhecimento no centro do debate. Por isso, os seus fundamentos teóricos apoiam-se mais em teorias sobre os idosos e no envelhecer, do que nas teorias educativas e daí haver diferenças com a gerontagogia. É dúbio o entendimento desse 'aprender' naquele ciclo de vida, em função dos interesses, necessidades socioeducativas e preocupações de quem promove este tipo de educação. Mesmo o aparecimento do termo 'geragogia', por M. Tayler em 1983, como sendo a educação de pessoas adultas maiores por pessoas da mesma idade, não se vinculou nesta área científica da gerontologia, nem tão pouco a'geriagogia' (vinculada aos défices dos idosos e à geriatria), pois foram submetidas a crítica por A. Lemieux (1997, p. 87-96), propondo o termo'gerontagogia'. Essa ciência educativa seria interdisciplinar com o objeto de estudo da pessoa adulta maior em situação pedagógica (campo de intervenção das ciências da educação). Trata-se duma ciência aplicada, tal como a pedagogia tem uma base teórica (psicopedagogia), a gerontagogia teria a gerontologia como sendo o seu alicerce de intervenção. Cremos que aqui renasce um debate orientador para a educação as pessoas adultas maiores no contexto da sociedade do conhecimento e do 'aprender a aprender ao longo da vida'.

Por conseguinte, A. Lemieux (1997, p. 26-38) intentou esclarecer semanticamente a gerontologia e gerontagogia. Enquanto a primeira se situa no campo da intervenção da gerontologia (envelhecimento), a segunda localiza-se no referente da educação da pessoa adulta maior e na 
aprendizagem permanente. Há um ponto de reflexão entre a gerontologia educativa ou educacional de influência anglo-saxónica) e a gerontagogia, de tal ponto que a primeira parece ser uma especialidade da gerontologia e a segunda como uma área das ciências da educação. Quer uma quer outra defendem e partilham espaços científicos diferentes (GARCÍA MÍNGUEZ, 2004). A gerontologia educativa parte da existência da gerontologia como ciência, que tem por objeto o idoso ou adulto maior e os fatores relacionados com o envelhecimento e velhice, ou seja, as pessoas maiores aparecem mais como adultos maiores que 'pessoas' (WITHNALL, 1992, p. 19-23).

Peterson (1976) e até Glendenning (1985) encerram a teoria e a prática da educação dos adultos maiores no âmbito da gerontologia que nas ciências da educação e, muito menos na pedagogia social/educação social. O ser'velho', 'idoso,' 'adulto maior' ou 'adulto tardio'e até'terceira idade' marca o processo educativo. Ora, bem na nossa perspetiva a gerontagogia está impregnada na educação, preocupa-se mais pela aprendizagem, do que pelo facto de os educandos serem adultos maiores (SORIA, 2012).

O questionamento pela educação e pela aprendizagem permanente nessas pessoas antecede a referência ao envelhecimento, velhice e sujeitos envelhecidos. Nesta disjuntiva opcional cabe reformular, não só a gerontologia educativa do vínculo à educação de adultos e gerontologia social, como a gerontagogia no novo paradigma da aprendizagem permanente. $\mathrm{A}$ valorização da gerontagogia depende do desprendimento e independência da gerontologia (psicológica, biológica e social) e da gerontologia educativa. Essa mudança de perspetiva de se justificar o campo científico antepondo o envelhecer (objeto de estudo da gerontologia educativa) à finalidade da educação não se enquadra na gerontagogia em que o seu objeto teórico-prático é o ensino e a aprendizagem dos adultos maiores e, por isso, o seu âmbito de intervenção é mais as ciências da educação do que a gerontologia. Esta questão coincide com aquela de que a pedagogia dependia da psicologia da educação e da aceção restrita de ser a ciência da educação das crianças e jovens. Parece-nos que cabe ao educador dos adultos maiores ou adultos e não o gerontólogo o que se ocupe da intervenção socioeducativa e cultural dessas pessoas (SÁEZ CARRERAS; ESCARBAJAL, 1999, p. 102-135). 
Polinização mútua entre educação dos adultos maiores e pedagogia social

As universidades para a terceira idade (universidades da experiência ou universidades seniores) têm demonstrado que as perceções das pessoas maiores mudaram com essas e em outras instituições a satisfação educativa e cultura que necessitam para um desejado envelhecimento ativo. Glendenning (1985, p. 10-14) preocupou-se por esse 'aprender' como um 'direito social', revendo os pressupostos teórico-concetuais, sociais, culturais, políticos e económicos que legitimam esses coletivos, considerando a gerontagogia como prioritária nas investigações empírico-analíticas e qualitativas no'com', no 'para' e a partir das pessoas maiores como protagonistas, manifestando conhecimentos de atividades e partilhando experiências, superando o paradigma funcionalista (transmissão de conhecimentos ou instrução), que dava uma perceção negativa da velhice (SÁEZ CARRERAS; ESCARBAJAL, 1998).

De facto, essas pessoas são vistas como um problema social e cultural que altera muitas das teorias e discursos no campo da gerontologia social. A questão resultante desta modificação assenta no tipo de educação e formação que possa contribuir para a qualidade de vida desses coletivos, já que a educação parece algo desejável em si mesmo, sempre que o modelo educativo mais favorável se adeque à diferenciação dessas pessoas, possibilitando-lhes uma transformação de novas experiências. Daí que as investigações nas ciências da velhice se associa à intervenção educativa que dela resulta (SÁEZ CARRERAS, 1996, p. 13-15), visualizando o poder da aprendizagem nessa idade (novas destrezas e perspetivas), com implicação na autonomia e atividade mental. Essa nova conceção de educação nos adultos maiores permitirá uma construção pessoal e social, como processo de comunicação nas diversas dinâmicas do aprender, num intercâmbio de significados do que Ihes preocupa, resolvendo-lhes as necessidades ou satisfazendo motivações e expetativas desejadas (SORIA, 2012, p. 101-105).

A gerontagogia (LEMIEUX, 1987, p. 214-217) vai ao encontro dessas diversidades desse coletivo de adultos maiores, que exigem uma formação, com estratégias educativas, que melhorem o estado físico, psíquico e mental e social, de modo a contribuir para a compreensão do ambiente que os envolve 
para viverem melhor e ativamente. Essa 'necessidade' educativa e cultural é interpretada como uma 'discrepância' do que possuem em realidade, como uma preferência ou desejo que determina as perceções dessas pessoas, sabendo que têm nesse ciclo de vida 'deficiências' ou 'ausências' que desejam colmatar. Por isso, as 'necessidades' são carências e problemas que se devem detetar e dar solução, incluindo o desenvolvimento de ser pessoa (aprender ao longo da vida), o saber como'poder fazer'algo diferente (individualização), de modo a terem uma participação mais ativa de cidadania.

Reequacionar a educação de adultos no contexto dos seus destinatários

Estamos numa sociedade que demograficamente envelhece, numa sociedade para todas as idades e gerações, que aprende (comunidades de aprendizagem) e as instituições para os adultos maiores aumentam rapidamente. Essas pessoas aproveitam as oportunidades para aprender, de forma diferente que em etapas anteriores, e o estudo da educação, a gerontologia educativa ou a gerontagogia vai imperando na área duma aprendizagem permanente ou um domínio da educação de adultos. Ou seja, a educação da terceira idade ou do adulto maior é o reflexo da educação não vocacional de adultos relativo a uma geração (SÁEZ CARRERAS; ESCARBAJAL, 1999, p. 56). Assim, houve uma emergência da educação de adultos, com uma índole de profissionalização, a exigência de novas áreas de estudo adequadas a essas pessoas adultas maiores.

A ideia de que os adultos podem continuar a aprender ao longo da vida fez assumir uma perspetiva não profissional da educação de adultos de optativa e voluntária, não acreditada e de ocupação do tempo livre ou de ócio. Houve uma preocupação por levar este tipo de educação, não só à classe média desses coletivos, mas a outras classes mais desfavorecidas ou baixas, impregnando-se de caraterísticas de movimento social com a missão de oferecer conhecimento aos que não estavam formados ou não tinham qualquer formação com o ideal de 'aprender por aprender'.

De facto, essa forma de educação de adulto não deixou de reproduzir as condições sociais e culturais de cada momento histórico e da natureza da 
sociedade. Nesse sentido, algumas teorias da educação foram revistas com o surgimento da sociedade do conhecimento ao exigir maior qualificação profissional, maior conhecimento para o exercício do desempenho, surgimento da educação e formação superiores e desenvolvimento de recursos humanos ao nível da profissionalização, de tal modo que surgiram novas profissões e novas formas de formação. Já na década dos 60 e 70, M. Knowles tinha popularizado a ideia de andragogia versus pedagogia, distinguindo cada uma delas. Contudo, a ideia de educação na terceira idade e nos adultos maiores não encontrou lugar nessa ideia de andragogia e, por isso surge o termo gerogogia e 'humanagogia'. Ora bem, esse debate e distinção terminológica, não muito bem aceito, fez com que surgisse a gerontologia educacional e, posteriormente a sua alternativa, a gerontagogia (LEMIEUX, 1987, p. 215217; PETERSON, 1976, p. 62). Atualmente a maior parte dos países ocidentais aceitam a ideia de aprendizagem permanente, onde se inclui a educação permanente. A questão emergente é se essa formação permanente segue ou não a ideia dominante de formação profissional, o que implica uma marginalização da educação para os adultos maiores ou pessoas da terceira idade (MARTINS, 2013).

Os relatórios internacionais, por exemplo o da 'União Europeia sobre a Sociedade que Aprende', nos finais da década de 90, remetia para a necessidade de um conhecimento amplo para o trabalho ou construindo habilidades para o emprego. Assim, a emergência da sociedade do conhecimento, da sociedade digital e globalização obrigou a mudanças na educação profissional. $O$ centro da educação de adultos nos finais do século passado estava na educação profissional de adultos e menos na educação geral de adultos. Um dos exemplos foi o aparecimento, nos países anglo-saxónicos e de alguns países europeus, de cursos de educação pré-aposentação que ajudam as pessoas a pensar sobre a importância da vida depois do trabalho produtivo. A própria formação contínua não manteve o seu predomínio nesses finais do século, devido à redescoberta da educação permanente (RIERA, 1998, p. 43-76). Essas modificações nos materiais de aprendizagem implicam que os objetivos desta educação passe a ser 'aprender' e o conceito dominante 'aprendizagem permanente', incluindo na terceira idade e/ou nos adultos 
maiores, que demonstram continuar a aprender na sua idade, crescendo a sua inteligência cristalizada, utilizando exercícios mentais sofisticados.

Nem todas as pessoas adultas maiores pretendem adquirir educação para qualificar-se. Observamos que o 'currículo' de educação de adultos da geração anterior converteu-se numa ementa para a aprendizagem dessas pessoas da terceira idade ou adultos maiores. Muitos deles viveram, como adultos jovens, a difusão da ideia de educação de adultos não-profissional. Cremos que as próximas gerações, que continuando a sua aprendizagem na vida laboral, podem modificar a educação de adultos e as suas temáticas, nesse desejo de ter mais educação e cultura depois da jubilação. Tudo isto obriga que os novos profissionais gerontólogos ou outros cuidadores da sua saúde (demências, deficiências) necessitem de competências e treino na aprendizagem dos adultos maiores (SÁEZ CARRERAS, 1996, p. 10).

\section{A APRENDIZAGEM NAS PESSOAS MAIORES: PRESSUPOSTOS E DESAFIOS}

Sabemos que a educação das pessoas adultas maiores é um direito social. Trata-se de inculcar a todo o cidadão o convencimento de que é uma parte ativa da sua própria história, numa participação consciente e responsável. Dessa forma, a cultura é um elemento fundamental a ser adquirido pela aprendizagem, num processo dinâmico de formação-modificação de si mesmo no contexto histórico-social. A educação das pessoas adultas maiores pode ser um elemento de transformação social, tendo na comunicação (construção social) a capacidade de provocar curiosidade de participar, a partir da própria experiência, a solidariedade, o respeito e a autoestima (JARVIS, 1993). Por isso, não podemos considerar esse tipo de educação como permanente-compensatória de objetivos escolares, já que se pretende uma sociedade de aprendizagens para todas as idades ou gerações (sociedade reflexiva e intergeracional). Esse tipo de aprendizagem baseia-se em interesses: aprendizagem instrumental orientada à resolução de problemas relevantes para a pessoa e a sua relação com o meio (aprender esquemas de significado); aprendizagem dialógica apoiada na procura de consenso na comunicação intersubjetiva; aprendizagem autorreflexiva orientada à compreensão de si 
mesmo proporcionando mudanças; aprendizagem participativa e colaborativa que produz reflexão das pessoas sobre as suas necessidades e gera habilidades (GARCÍA MÍNGUEZ, 2004; GARCÍA ; SANCHÉZ, 1998).

Lembremos que há um leque de fatores referentes às pessoas adultas maiores e à sua aprendizagem que se devem ter em conta no momento da educação gerontológica: mudanças nas capacidades físicas fisiológicas no envelhecimento; mudanças nas capacidades sensoriais (auditivas, visuais); mudanças relacionadas com a velocidade (lentidão do comportamento) e mobilidade; mudanças de atitudes e reações pessoais; mudanças cognitivas (memória elemental, secundária e terciária); mudanças morais e de adaptação; capacidades de aprender e desenvolver-se por si mesmos.

Sabemos que a educação dos adultos maiores converteu-se numa reflexão social, pedagógica e de intervenção que se expandiu e consolidou com programas, planos e experiências cada vez mais fundamentados. Simultaneamente, surgiu o contributo de uma saga de teorias de várias áreas científicas explicativas do envelhecimento e velhice (biológicas, psicológicas, sociais, pedagógicas), que incorporaram conceitos tais como o envelhecimento ativo/exitoso, empoderamento, intergeracionalidade, etc. Todo este campo de conceptualização implica acções e perfis de profissionais que nos questionam novos desafios. Essa finalidade processual, de melhoria e transformação da educação no processo de envelhecimento das pessoas adultas maiores, apoia-se na forma e estilo de vida de envelhecer, encontrando-se muitas delas com algum nível de instrução e conhecimentos práticos importantes em termos de vivências e de participação. Pois bem, centremo-nos nessa importância de'aprender ativamente', de modo a refletirmos propostas educativas para que se configure uma nova compreensão do processo de envelhecimento e da velhice, mais positivo, mais satisfatório e otimista, aberto às mudanças e ao desenvolvimento das capacidades, para além dos naturais declives e perdas. De facto, a educação nas pessoas pós-aposentadas ou na velhice tem uma exigência reflexiva, quer nos objetivos ou finalidades, quer nas metodologias de intervenção ou ação sobre esses sujeitos que são atores e protagonistas desse processo. 
Pensamos que há um conjunto de perceções positivas sobre as possibilidades educativas das pessoas maiores nas instituições (universidades, associações), devido à satisfação sociocultural e educativa que manifestam nas suas atividades e acções.

As razões, que sustentam as necessidades educativas e/ou formativas dessas pessoas na sua promoção pessoal e social, exigem uma política (apoio público) à aprendizagem nesses estádios de vida. Glendenning (1985, p. 9-13) admite que essas propostas educativas não devem ser 'slogans' chamativos com finalidades políticas, mas sim um direito social, ou um aprender para seguir avançando nesse período de vida. Ambos especialistas exigem uma revisão teórica, social e cultural na legitimação da educação dos adultos maiores, não como uma moda, mas como um motivo de incremento de investigações (empírico-analíticas e qualitativas) neste campo das ciências da velhice, destacando a afirmação da gerontagogia nesses estudos ('com', 'nos', 'para', 'a partir' das pessoas adultas maiores). Esse sentido exploratório e descritivo, analítico e interpretativo dessas investigações no processo educativos dessas pessoas permitem extrair conhecimento sobre as atividades e as formas interventivas desses protagonistas e atores, superando o paradigma funcionalista que nos dá uma perceção negativa da velhice (SÁEZ CARRERAS; ESCARBAJAL, 1998, p. 87). Discursos, olhares concetuais ou perspetivas surgem nessa desqualificação dos paradigmas dominantes sobre o envelhecimento e velhice, de que os 'idosos, 'adultos maiores' ou as pessoas da terceira e quarta idade' não são produtivas e participativas.

É verdade que uma das nossas preocupações centra-se no tipo de educação e formação que pode melhorar a qualidade de vida e a satisfação para a vida dessas pessoas (BLÁZQUEZ; HOLGADO, 2011, p. 146-149). A educação e a cultura são sempre desejáveis, contudo o problema consiste em consensualizar o modelo de educação mais favorável ao tipo de pessoas: desde a transmissão de conhecimentos a uma simples instrução, ou da partilha de saberes e experiências à compensação ou ampliação crítica e contextual de novos saberes. Nesse aspeto, o âmbito das instituições de ensino superior, os equipamentos ou instituições para pessoas adultas maiores e as associações e centros de convívio são espaços de intervenção socioeducativa e cultural, que 
deve incluir os serviços sociais e assistenciais (MARTINS, 2013). Por exemplo, o papel da'British Open University's Older Adults Research Group'é um modelo no âmbito das investigações etnográficas sobre a educação nessas pessoas, de tal modo que ampliou redes de estudos em outros países, destacando a melhoria na saúde, bem-estar e satisfação para a vida, aumento das capacidades de compreensão e reflexão como compensação do enfraquecimento do estado físico- mental. Nos novos cenários sociais parece obsoleto a relação da educação com atividade social produtiva.

\section{Programas (INTER)geracionais: Desafio do SÉCULO}

Sabemos que não existe uma consciência social de evolução da pessoa ao longo da vida e esse facto dificulta que se prepare para o envelhecimento. $\mathrm{O}$ ser humano que envelhece tem a tarefa de adaptar-se às próprias mudanças do seu organismo como deve conseguir adaptar-se ao meio envolvente e como o percebe (maneira diferente) (CUENCA et al., 2011, p. 254-259) Qualquer programa de intervenção socioeducativa com a finalidade de realização pessoal e participação social das pessoas adultas maiores e com outras gerações (retroalimentação) deve basear-se numa educação interativa com as seguintes caraterísticas: estrutura não formal da educação, com atividades livres com o objetivo de contribuir para o seu desenvolvimento pessoal, bem-estar, satisfação e qualidade de vida (DOWD, 1994, p. 21); as finalidades dessa educação são a realização pessoal e o compromisso social, no desenvolvimento de competências/habilidades sociais e individuais, numa troca de vivências e experiências num compromisso com as outras gerações; a interavidade contempla-se como método e objetivo para uma maior participação, na recuperação da cultura e tradições populares e memória histórica.

Nessa pretensão de melhorar a qualidade de vida daqueles coletivos de adultos maiores, a educação permite uma ação de mudança, como uma ação fenomenológica orientada a possibilitar a descoberta do capital pessoal, social e cultural, de maneira a transformar e a reconhecer este coletivo (GIL CALVO, 2003). Os programas de educação gerontológica 
e/ou gerontagogia geram relações convivenciais, compensações sociais, cuidados do ser e o'estar com pessoas' (melhoria dos contextos culturais). A metodologia pedagógica com essas pessoas assenta nos princípios de atividade, independência, protagonismo e participação de modo a aproximar-se às outras gerações.

É importante a educação intergeracional, pois constitui o veículo de transmissão de conhecimento e sabedoria entre gerações, fortalece as redes sociais, tão necessárias para os adultos maiores e, ainda o desenvolvimento da cidadania, do voluntariado e empreendorismo. A efetividade das redes sociais determina-se pelo número de pessoas que a integram, a diversidade dos vínculos (familiares, emocionais, sociais, culturais) e a variedade de recursos que promovem. Por isso, os programas intergeracionais e/ ou os gerontológicos proporcionam o desenvolvimento pessoal/social e a qualidade de vida, relacionando-se com as redes sociais. A revalorização da história e do tempo histórico vivido, a experiência e as narrações dos adultos maiores são fundamentais para conseguir uns entrelaços geracionais, projetar uma nova visão da velhice, fortalecer a pessoa como tal e continuar a aprender a aprender. $O$ contributo dos programas intergeracionais implica o reforço de ferramentas necessárias para que a pessoa adulta maior se sinta membro ativo da sociedade (cidadania participativa), protagonista dos saberes partilhados e produtor de uma economia emergente familiar e comunitária.

A pretensão de uma sociedade para todas as idades e para todas as gerações consegue-se com cidadãos que sejam protagonistas da aproximação à sua história (memória), pela comunicação/diálogo, com a participação ativa para consolidar o sentido comunitário e refletir sobre os benefícios da educação (inter)geracional e intercâmbio de experiências e saberes. Sabemos que cada um de nós tem uma história diferente, que depende da forma com que a vivamos e a experienciamos, mas o importante é vincular essas histórias entre gerações, onde cada um aprenda do outro, independentemente da idade, do momento histórico, experiência e cultura. Desse modo consegue-se uma filosofia de encontro geracional e uma interação comunitária e cidadã. 


\section{(IN) CoNCLUSÕES DE REFLEXÃo}

A nossa análise sobre a educação dos adultos maiores e a sua aprendizagem, no contexto da pedagogia social (PS) apontou para algumas considerações de reflexão:

-Repensar os objetivos e metas da educação social orientadas `a construção duma cidadania democrática e social, de convivência e participação comunitária, em que os processos de socialização e sociabilidade dos adultos maiores, na continuação do seu projeto de vida e do'ser pessoa', aprendendo das experiências e da inclusão de novos saberes e habilidades, necessitam dos referentes de várias ciências (interface: ciências da velhice e ciências da educação) (AMORÓS et al., 2006, p. 32-65). A PS empenha-se em construir modelos educativos orientados às práticas socioeducativas e culturais, incorporando as condições sociais e as diversas necessidades dos adultos maiores.

-Os processos de socialização, materializados na prática da educação social, implicam que a educação dos adultos maiores seja motivadora, que incorpore cada pessoa ao espaço social e cultural em que está inserido e essa finalidade consegue-se pela vertente educativa. Na educação de adultos maiores, eles são os protagonistas do 'aprender', do que querem aprender e partilhar (saberes, experiências), pois o que os carateriza como ser social e cultural, é a sua capacidade de tomar decisões e decidir em cada momento o que 'fazer', mediante os seus interesses e finalidades. Essa polinização de territórios e discursos, emergentes na transversalidade, faz com que a PS e a educação intergeracional (programas) considerem os adultos maiores sujeitos da educação e agentes educativos. Por isso, a relação educativa com a gerontagogia (LEMIEUX, 1987, p. 215-218).

-A relação estabelecida entre os educadores/profissionais e os destinatários/adultos maiores é mais uma relação educativa e cultural que pessoal (assimétrica), numa partilha de competências, capacidades e experiências em que as pessoas são mais importantes que os métodos e conteúdos culturais a transmitir, em que os profissionais gerontólogos ajudam a incorporar-se nos espaços sociais da sua época (GARCÍA; SANCHÉZ, 1998). Os modelos 
educativos articulam-se com o termo profissionalização e as competências qualificadoras à prática educativa com esses coletivos, dependendo das políticas sociais e educativas vigentes (RIERA, 1998, p. 21-34).

Pensamos que a gerontagogia é esse espaço científico híbrido de prática educativa resultante dos laços de diferentes especialidades, entre elas a gerontologia, sem prescindir de outras no âmbito da multidisciplinaridade do envelhecimento e das ciências da velhice. Essa prática é prioritariamente ensino e aprendizagem de pessoas, que são diversas entre si, que se relacionam num contexto e com uma vida pessoal e social própria (experiências, habilidades acumuladas) que pretendem ter satisfação, felicidade e qualidade de vida nesse ciclo de vida. Não se trata de uma tautologia de palavras, mas incidir, como um bisturi, nos diversos enfoques educativos e culturais, que intervêm nas pessoas da terceira idade ou adultos maiores. Não é o idoso/ idosa o que nos ocupa na tarefa da gerontagogia, mas sim a 'pessoa', o ser humano, com uma determinada idade, com a sua história ou biografia de vida e com direito a aceder aos recursos e a ter uma capacidade de ação e a saberes concretos e necessários. Assim, a gerontagogia é uma prática e o'gerontagogo'é um interventor de proximidade, um profissional da intervenção, que orienta as suas funções para o intercâmbio de saberes, a comunicação, a partilha de competências/habilidades, possibilitando o desenvolvimento e capacitação desses adultos maiores no seu projeto de vida, qualidade perante a vida.

EDUCATING ELDER ADULTS IN THE SOCIAL EDUCATION AREA:THE INTERGENERATIONALITY IN A SOCIETY FOR ALL AGES

ABSTRACT: The theme of education of adults and/or elder adults deserves an epistemological reflection in relation to the action of professionals, in the various valences in the social and community networks, as well as in the educational institutions. Using a hermeneutic argument the author approaches the need of implementing educational proposals for elder adults, in the field of Gerontology education or gerontagogy, integrating these actions in the context of social education/pedagogy. The objectives that guided the phenomenological analysis are: rethink elder adult education, in the area of gerontagogy; analyze the socio-educational, psycho pedagogical and methodological aspects in the actions and in the gerontology programs, with the purpose of promoting active citizenship. We will epistemologically reflect the educational 
possibilities, from socialpedagogy/social education and gerontagogy, in order to give a quality of life for elder adults in a society for all generations.

KEYWORDS: Elderly education. Educational gerontology. Social education. Intergenerationality.

\section{EDUCAR A LOS ADULTOS MAYORES EN EL ÁREA DE LA EDUCACIÓN SOCIAL: LA INTERGENERACIONALIDAD EN UNA SOCIEDAD PARA TODAS LAS EDADES}

RESUMEN: El tema de la educación de adultos y/o adultos mayores merece una reflexión espistemológica, en relación a la acción de los profesionales, en las diversas valencias en la red social y comunitaria, como en las instituciones educativas. Utilizando una argumentación hermenéutica, el autor aborda la necesidad de implementar propuestas socioeducativas para los adultos mayores, por medio de programas intergeneracionales, destacando el papel de la educación de gerontología o gerontagogía, el cual se integraen el campo de educación social. Los objetivos que guiaron nuestro análisis fenomenológico son: repensar la educación de adultos mayores, en la zona de gerontagogía; analizar los aspectos socioeducativos, psicopedagógicos y metodológicos en las acciones y programas gerontológicos, con la finalidad de promover la ciudadanía activa. Pretendemos refletir epistemológicamente las posibilidades educativas, provenientes de la pedagogía social/ educación social y la gerontagogía, con el fin de dar mejor calidad de vida para los adultos mayores, en una sociedade para todas las generaciones.

Palabras Clave: Adulto mayor. Gerontología educacional. Educación social. Intergeneracionalidad.

\section{REFERÊNCIAS}

AMORÓS, P. et al. Construyendo futuro. Las personas mayores: una fuerza social emergente. Madrid: Alianza Ed., 2006.

ARNAY, J.; MARRERO, J.; FERNÁNDEZ, I. Las universidades para mayores: Qué enseñanza, qué aprendizaje? Revista de Ciencias de la Educación, 225-226, p. 89-106, 2011

BERMEJO, L. Gerontología Educativa. Cómo diseñar proyectos educativos para personas mayores. Madrid: Editorial Médica Panamericana, 2005

BLÁZQUEZ, F.; HOLGADO, A. Innovación educativa en programas universitarios para mayores. Revista de Ciencias de la Educación, 225-226, p. 129-150, 2011. 
CUENCA, M. et al. Ocio experiencial en la universidad: Programa Multigeneracional de Cultura y Solidariedad. Revista de Ciencias de la Educación, 225-226, p. 251-269, 2011.

DOWD, I.I. 'Aging as exchange'. Journal of Educational Gerontology, 9, 16-27, 1994.

GARCÍA MÍNGUEZ, J. La educación en personas mayores. Ensayo de nuevos proyectos. Madrid: Narcea, 2004.

GARCÍA, J.; SANCHÉZ, A. Un modelo de educación en los mayores: la interactividad. Madrid: Dykinson, 1998

GIL CALVO, E. El poder gris. Una nueva forma de entender la vejez. Madrid: Mondadori, 2003.

GLENDENNING, F. 'What is educational gerontology? North American and British definitions'. In: F. GLENDENNING (Ed.), Educational Gerontology. International Perspectives. New York: St Martin Press, 1985. p. 31-57.

GLENDENNING, F. 'What is the future of Educational Gerontology'. Ageing and Society, II, p. 209-216, 1990.

JARVIS, P. Adult Education and the State. Towards a Politics of Education. New York: Routledge, 1993

LEMIEUX, A. 'Gérontologie educative et gérontagogie'. Lánnée Gerontologique, n. 3, p. 213-219, 1987.

LEMIEUX, A. Los programas universitarios para mayores. Madrid: INSERSO, 1997

MARTINS, E.C. Gerontologia \& Gerontagogia. Animação sociocultural em idosos. Lisboa: Cáritas Editorial, 2013.

MORENO, M. Bedmar \& GARCÍA, I. Montero (Coord.) La educación Intergeracional: Un nuevo ámbito educativo. Madrid: Dykinson, 2003.

MOSKOW-McKENZIE, D. \& MANHEIMER, R. Older Adult Education. A Guide to Research. Programs and policies. Connecticut: Greenwood Press, 1995

PETERSON, D.A. 'Educational Gerontology: The State of the Art'. Educational Gerontology, 1 (1), p. 62-64, 1976.

RIERA, J.P. Concepto, formación y profesionalización de: El educador social, el trabajador social y el pedagogo social. Valencia: Nau Llibres, 1998.

SÁEZ CARRERAS, J. 'Reconstruyendo el discurso educativo de la tercera edad'. Pedagogía Social, n. 13, p. 5-15, 1996.

SÁEZ CARRERAS, J. \& ESCARBAJAL, A. La educación de personas adultas: en defensa de la reflexividad crítica. Salamanca: Amarú, 1998. 
SÁEZ CARRERAS, J. \& ESCARBAJAL, A. La reflexividad crítica en la educación de personas adultas. Salamanca: Amarú, 1999.

SORIA, V. El aprendizaje basado en problemas (ABP). Una propuesta metodológica para la formación de adultos/as. Diálogos, 70, p. 43-50, 2012.

WITHNALL, A. 'Towards a Philosophy of Educational Gerontology: The unfinished debate'. Journal of Educational Gerontology, Vol. 7 (1), p. 16-24, 1992.

ERNESTO CANDEIAS MARTINS: Doutor em Ciências da Educação pela Universitat de les Illes Balears (Palma de Mallorca - Espanha). Docente do ensino superior desde 1988, Departamento Ciências Sociais e Humanas da ESECB, coordenador de cursos de Mestrado, Investigador integrado do CeiED da Universidade Lusófona de Lisboa, membro de sociedades e associações de pedagogia e/ou Ciências da Educação, membro da comissão cientíitica de várias revistas nacionais $e$ internacionais. Tem publicado uma vasta obra de livros e artigos da especialidade.

E-mail:ernesto@ipcb.pt 